\title{
Alois Riegl.
}

Alois Riegl wurde am 14. Jänner 1858 in Linz in Oberösterreich geboren. Er hatte sich zuerst zuerst den juridischen Studien zagewendet, trat aber bald an die philosophische Fakultät über, wo er angezogen von der gewaltigen Persönlichkeit Theodor von Sickels sich den historischen Hilfswissenschaften zuwendete. Er wurde 1881 in das Institut für österreichische freschichtsforschung als wirkliches Mitglied aufgenommen, leirte 1 s8:3 die Institutsprüfung ab und promovirte am $\%$. Dezember desselleen Jahres in Wien als Doktor der Philosophie. Schon wäbrend der Institutsjahre batte er sich unter Thausing der Kunstgeschichte zugewendet und fleich mit einer seinen ersten Arbeiten einen wichtigen Beitr.ıg zu seiner Fachwissenschaft geliefert. Nachdem eine kleine Irbeit über ein angiovinisches Gebetbuch der Wiener Hofbibliothek vorangegangen (im 8. Bande dieser Zeitschrift), veröffentlichte er im 10. Bande seine Untersuchungen über mittelalterliche Kalenderillus!rationen. Er wies an diesem Materiale zum erstenmale die wichtige Tatsache nach, dass in 10. Jabrhundert neue hompositionen ersonnen wurden, nachdem bis zu dieser Zeit noch immer die antiken Kompositionen vorgehalten hatten, die regelmässig nuchgebildet wurden. Er setzte aber dadurch den wichtigen Einschnittspunkt zwischen antiker und moderner Kunst fest, was bis dahin mit gleicher Prăzision nuch nicht geschehen war. Im Jahre $1 \$ 86$ trat Riegl in das österreichische Yuseum für Kunst und Industrie ein und übernahn die Leitung der T'extilsammlung. Es war das kurz nach dem Tode Rudolfs v. Eitelberger, wo das Museum unter der Leitung Jacobs ron Falke, noch ein Mittelpunkt geistiger Bestrebungen und wissenschaftlicher Kultur geblieben war. Nun wandte er sich der Erforschung der Geschichte des Ornamentes zu. Man war bisher der Meinung gewesen, das sogenannte orientalische Ornament, wie es uns besonders in der Musterung der persischen Teppicine entgegentritt, stamme aus der alten vorhellenischen Ornamentik Mittelasiens ab, ohne dass man je den Zusammenhang des Nähern nachgewiesen hätte. Riegl entdeckte nun, dass diese Ornamentik sich ebenso wie die romanische in Westen und die byzantinische im Osten aus der hellenistischen entwickelt babe ${ }^{1}$. Das ist eine der grössten Bereicherungen der allgemeinen Kunstgeschichte, ibre Bedeutung ist selbst heute noch nicht allgemein erfilsst worden. In weiterer Verfolgung dieser Beobachtung kam Riegl auch darauf, dass sich selbst ein Teil der ostasiatischen Ornamentik auf hellenistische Anregung zurückführen lasse. Das Jahr 1893 brachte seine Stilfragen, eine Untersuchung über Entstehung und Geschichte der wichtigsten griechischen Ornamente der Ranke und Palmette. Er verfolgte die Motive hijs in ibre ägyptische und mykenische Stufe zurück und zeigte ihre ständige Ausbildung und Umbildung, wobei er kein gelegentliches Neueingreifen von Naturvorbildern zugeben wollte. An der Universität babilitirte sich Riegl 1889, er wurde im Jahre 1895 ausserordentlicher Professcr, 1897 ordentlicher. Das Museum für Kunst und Indastrie hatte er nach elfjähriger Dienstzeit. verlassen, nachdem sich dort alle Verhältnisse so geändert hatten, dass sie ihm ein gedeihliches Wirken nicht weiter möglich gemacht bätten. Er batte dort mit seinem damaligen Kollegen Masner zu-

1) A. Kiegl, Orientalische Teppiche 1891. 
sammen, der gegenwärtig Direktor des Museums in Breslau ist, eine Arbeit begonnen, die eine Publikation aller spätrömischen Werke der Kunstindnstrie werden sollte. Davon kam bisber nur der erste von Riegl gearbeitete Band zu Stande (1901), wo Riegl wieder die Probleme ganz neuartig anfasste und löste. Hatte man bisher geglaubt, dass die nordischen Völkerscbaften Kunstmotive aus ihrer Urheimat witbrachten, die allmälig in die klassische Kunst eindrangen und deren Formen ablösten, wollte er zeigen, das: diese vermeintljchen Motive nichts anderes seien als eben die Motive der hellenistisch-römischen Kunst in ihrer derzeitigen Entwicklung. In dem ersten Bande zeigt er nun, wie sich vom 7.weiten Jahrbundert der Kaiserzeit in der Stil zu wechseln begann, dass das subjektive Element, dass die Darstellung des Gegenstandes vor dem Auge des Beschauers, die Licht- und Schattenwirknng immer mehr die objektive Nachbildung des Gegenstancles überwand, wie überhaupt in einer Zeit, die man für eine Zeit des Verfalles hielt. neue Kunstprobleme auftauchen, die die folgenden Jahrhunderte weiter zu bilden bätten.

Als Lehrer wirkte Riegl sebr anregend und besonders seine Geschichte der Barocken gebört zu baben, wird von allen seinen Schülern, die ihn aufzufassen in Stande waren, als ein wichtiges Ereiguis ibres Lebens empfunden. Ich kann mir das wobl vorstellen. Ith hatte ihn einmal zufällig in der Nähe von Piazza Venezia in Rom getroffen und wie wir den Corso hinunter wandelten, erleuterte er mir Façade für Façade von Kirchen und Palästen. Es war eine Fülle von neuen Einblicken, die ich in die Geschichte der Barockarchitektur gewann.

Die letzten Jahre seines Lebens hat er hauptsächlich der Zentralkommission für Erforschung und Erhaltung der Kunst- und historischen Denkmale gewidmet. Er hat dieses schon etwas alt gewordene Institut in kurzer Zeit verjüngt, hat neues Leben in sie gebracht, ihr Jabrbuch und ihre Nitteilungen auf neue Basis gestellt, für die Regicrung hat er ein Denkmalschatzgesetz entworfen, das, wenn es einmal durchgeführt sein wird, ein Muster bilden wird, die Reorganisation der Zentralkommission angebahnt, in der scharfsinnigen Erledigung vieler Akten musterhafte Entscheidungen in den dieser Körperschaft zufallenden Agenden aufgestellt. Und das Alles, obwohl ihn eine schwere unheilbare Krankbeit exfasst batte, die aber seinen Eifer, sein scharfsinniges Urteil nicht erlahmen machten. Bis in die letzten Momente seines Lebens, kann man sagen, zeigte er sich umsichtig und tätig. Er wirkte noch fort für die Universität. für die Zentralkommission, für die Akałemie der Wissenschaften, die ihn $1902 \mathrm{zu}$ ibren korrespondirenden Mitgliede gewählt batte. Am 17. Juni 1905 ist er gestorben. Einige Tage vor seinen Tode wurde ihm Titel und Charakter eines Hofrates verliehen. Eine ausführliche Biographie Riegls bat Max Drořák in den Mitteilungen der Zentralkommission (3. Folge 4. Bd. S. $955 \mathrm{ff}$.) veröffentlicht.

Franz Wickboff.

\section{Viktor von Kraus.}

Nach längerem Leiden ist uns am 3. November 1905 Viktor v. Kraus entrissen worden. Mit $\mathrm{ibm}$ ist ein Mann von vielseitiger, fruchtbarer Wjrksamkeit dahingegangen. $\nabla$. v. Kraus war am 2. November 1845 in 